\title{
Dubet, François (2020) La época de las pasiones tristes. De cómo este mundo desigual lleva a la frustración y el resentimiento, y desalienta la lucha por una sociedad mejor. Buenos Aires: Siglo XXI. ISBN: 978-987-801-002-1
}

\author{
Martin Dragone \\ martin.dragone9@gmail.com \\ Universidad Nacional de La Plata, Argentina
}

\begin{abstract}
Cita sugerida: Dragone, M. (2020). [Revisión de La época de las pasiones tristes. De cómo este mundo desigual lleva a la frustración y el resentimiento, y desalienta la lucha por una sociedad mejor por F. Dubet]. Archivos de Ciencias de la Educación, 14(18), e093. https://doi.org/10.24215/23468866e093
\end{abstract}

François Dubet es un sociólogo, educador, investigador francés preocupado por analizar temáticas como la desigualdad, la educación, los procesos de individualización y las democracias modernas. En ese conjunto amplio, pero interconectado de problemáticas, podemos ubicar puntos de contacto en su obra. Efectivamente, destacamos allí una línea de trabajo abocada a pensar las vinculaciones entre diferentes dimensiones del análisis sociológico, que concibe que no se pueden entender determinados procesos sociales si no es integrando perspectivas analíticas solidarias. Con ejemplos como En la escuela. Sociología de la experiencia escolar (Dubet, 1998) o El declive de la institución (Dubet, 2006), la constatación de la multiplicidad de puntos de vista, de formas de vivenciar el mundo y sus vínculos, la subjetividad como parámetro de lo bueno y lo malo, se hace cada vez más clara. En un mundo construido por grandes 
instituciones que moldeaban gran parte de nuestras vidas, los nuevos fenómenos societales ponen en cuestión y en tensión su legitimidad y eficacia. Lejos de entenderlo como un salto cualitativo respecto a formas previas de organización y estructuración social, ve allí la continuación lógica de ese proceso. "Esta evolución no es ni posmoderna ni, desde luego, poscapitalista: prolonga y acentúa los rasgos de la modernidad” (Dubet, 2020, p. 47). Así, La época de las pasiones tristes (2020) se enmarca en esa tradición de preocupaciones y análisis que buscan desentrañar los nuevos modos de desigualdad, de injusticias, sus apropiaciones y respuestas por parte de las y los sujetos.

La obra está dividida en cuatro capítulos, que avanzan en plantear diferentes problemáticas de este nuevo tiempo. Busca aportar, asimismo, algunos interrogantes al debate, de manera desprejuiciada y lúcida sobre los procesos sociales en marcha.

El primer capítulo titulado "El fin de las sociedades de clase", llama la atención sobre un fenómeno político, sociológico, económico que se encuentra en la base de las transformaciones actuales. Las clases como ordenadoras sociales, grupos que funcionan como representación por parte de los partidos políticos, sindicatos, y que moviliza a la acción colectiva, está hoy en crisis. Por otra parte, el orden de la vida que proporcionaba el trabajo asalariado desde el nacimiento hasta la jubilación, es cada vez menos una realidad. La "desestandarización de las trayectorias"(Dubet, 2020, p. 29) implica la multiplicidad de recorridos que una persona llevará a lo largo de su vida: laborales, afectivos, ideológicos. Y la lista sigue. Así, la distinción entre la pertenencia a una clase u otra ya no opera como el factor decisivo, quizá ni siquiera como un factor relevante.

Esto nos lleva a mencionar el segundo capítulo, "El régimen de desigualdades múltiples". Una de las ideas más punzantes y complejas, que atraviesan el libro, es la idea que esboza el autor para dar cuenta de este nuevo régimen social. "Lo cierto es que cada conjunto de condiciones sociales puede complejizarse al infinito. Ni siquiera los grupos que parecen más homogéneos tienen una verdadera unidad" (Dubet, 2020, p. 38). Toda ilusión analítica de buscar factores explicativos debe detenerse ante la constatación de las desigualdades y las diferencias porque, si bien tienen puntos de contacto, no son lo mismo. Lo interesante del aporte de este capítulo es ayudarnos a borrar una imagen romántica de una sociedad ordenada por categorías predefinidas, transparentes. La complejidad es la regla, con múltiples combinaciones entre infinitas posibilidades y experiencias que atraviesan a las y los sujetos. En el campo educativo nos invita a mirar con más detalles cómo se producen las desigualdades y los efectos de distinción. Ya no se explica por factores económicos o culturales solamente; las interacciones cotidianas y micro procesos en las escuelas producen trayectorias que se van diversificando -y desigualan- a medida que se extienden en el tiempo. Allí hay un punto a ser registrado en toda su profundidad.

La política pública también es alcanzada por estos procesos al organizarse más por atributos específicos de cada beneficiaria/o que en base a criterios generales. Poseer un determinado nivel de ingresos, vivir en determinada zona geográfica, la situación conyugal, el tipo de empleo, son todas variantes que van constituyendo una categoría a ser alcanzada por las políticas sociales. Al fraccionarse en tantas esquirlas la sociedad, se rompen los hilos que unían a las personas por elementos comunes. Y se instalan lógicas de salvataje personales y desconfianza hacia las y los otros. Como afirma Dubet “(...) cualquiera puede tener la sensación de que lo estafan, de que paga demasiado y para quienes no lo merecen y de que no recibe lo que el mismo merece. Se imagina con facilidad que los otros reciben demasiado, cuando se ignora lo que reciben y lo que dan" (2020, p. 91).

El tercer capítulo del libro se titula "Experiencias y criticas de las desigualdades", donde a partir de un debate alrededor de los modelos de justicia -temas analizados con mayor profundidad en su libro "Repensar la justicia social" (Dubet, 2011)- se introducen las preocupaciones y texturas que atraviesan el libro. El tema fundamental del capítulo, que se suma a las argumentaciones que Dubet viene desarrollando, es la distancia cada vez más grande entre condiciones objetivas y percepciones subjetivas. Si bien no es una discusión nueva -¿se puede hablar de condiciones objetivas más allá de las interpretaciones de los sujetos? ¿No son las percepciones ya de por si una construcción con consecuencias objetivas particulares?-, es interesante 
pensar qué tipos de vínculos podemos establecer entre ambas dimensiones, y cuáles son los efectos que producen en la constitución de las sociedades. Lo que se deriva del análisis que propone el autor es que las desigualdades y su percepción no pueden jerarquizarse a partir de criterios objetivos -como el nivel de ingresos-. Lo que ocurre es que "(...) cuando se adopta el punto de vista de los individuos, las desigualdades 'en calidad de' se multiplican y singularizan los autoposicionamientos, las experiencias y las definiciones de si, más allá de las grandes categorías de desigualdades” (Dubet, 2020, pp. 57-58). Un apartado de este capítulo, "Compararse con quienes están más cerca", se detiene en analizar y plantear las consecuencias de la pérdida del sentido de colectivo y la posibilidad de que las situaciones compartidas nos permitan actuar juntas/os. Se opera una transformación desde las desigualdades de posición social hacia las características singulares de los individuos (Dubet, 2020, p. 63). En estas nuevas formas y escenarios, cada cual puede ser víctima y victimario, discriminado y discriminador. La cadena bidireccional sanciona la intercambiabilidad de las funciones y acciones, haciendo más porosas las distinciones sociales. En última instancia, la época que vivimos, es una época donde los grandes relatos se fragmentan y pierden su capacidad de enunciación, trasladando al sujeto la responsabilidad de definir qué es justo y qué no, digno o indigno de ser reconocido, y en qué momentos. Abrimos así el último capítulo de este libro.

En "Iras e indignaciones", una pregunta abre sus páginas, invitándonos a ser más cautas/os y desprejuiciadas/os para observar -y comprender- este tiempo: “QQué es esta economía moral que produce ira e indignación, sin ser capaz de reflexionar sobre sus causas?” (Dubet, 2020, p. 77). En épocas donde gran parte de la comunicación se da en redes sociales, una vinculación más inmediata (a un clic de distancia) y con menos mediaciones, se observa una característica particular de estas nuevas relaciones sociales. Podemos pensar qué implicancias y hasta qué niveles esto puede tener consecuencias en las escuelas, en un universo construido justamente para escapar a determinantes rápidos y permitir un espacio de tiempo libre, reflexivo (Masschelein y Simons, 2014; Bárcena, Valerio López y Larrosa, 2020). Si bien para Dubet esto implica graves consecuencias a nivel de las interacciones entre las personas, lo es aún más cuando constatamos su creciente uso en las campañas políticas. La segmentación del electorado, los discursos dirigidos para cada audiencia, derivan en una consecuencia a considerar: "La cuestión de la verdad ya no es verdaderamente pertinente: a cada uno la suya" (2020, p. 80).

La pregunta entonces que emana sería ¿Qué respuestas políticas puede haber ante la época de las pasiones tristes? En principio, la respuesta que brinda Dubet no es esperanzadora sobre el futuro. También, para las y los lectores latinoamericanos, el concepto "populismo" que utiliza merecería tomar en cuenta otros usos y tradiciones que disputan un sentido univoco de la palabra. En un momento, Dubet integra en una misma caja analítica a Perón, Chávez, los fascismos del '30; y, más acá, los populismos de Le Pen, Trump o Bolsonaro. Quizás, al reducirlos a una palabra, produce una mirada que pierde la complejidad que revisten los fenómenos políticos, y que no permite acercamientos que recuperen los apoyos, diferencias y contradicciones.

El texto de Dubet es una potente crítica a las sociedades actuales, sus instituciones y los nuevos vínculos que forjamos, entre nosotras y nosotros y con las tecnologías. Llamar la atención y preguntarse por sus derivas, sus peligros, y qué hacer para remediarlo son algunos de los aportes de este libro, contribuyendo así al debate de una nueva época, cuyos contornos estamos aun delineando.

\section{REFERENCIAS}

Bárcena, F., Valerio López, M. y Larrosa, J. (2020). Elogio del estudio. Buenos Aires: Miño y Dávila Editores

Dubet, F. (2020). La época de las pasiones tristes. De cómo este mundo desigual lleva a la frustración y el resentimiento, y desalienta la lucha por una sociedad mejor. Buenos Aires: Siglo XXI

Masschelein, J. y Simons, M. (2014). Defensa de la escuela. Una cuestión pública. Buenos Aires: Miño y Dávila Editores 